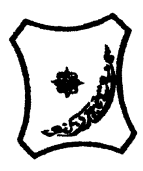

Bayero Journal of Pure and Applied Sciences, 12(2): 129 - 134

Received: October, 2019

Accepted: December, 2019

ISSN $2006-6996$

\title{
COVERAGE RESPONSE MODELING FOR AUTO BASE PAINTS FORMULATION
}

\author{
${ }^{1}$ Bello, A., ${ }^{1}$ Ameh, A. O., ${ }^{1}$ Isa M. T., ${ }^{1}$ Galadima M. S., and ${ }^{2} *$ Adeoye D. 0. \\ ${ }^{1}$ Department of Chemical Engineering, Ahmadu Bello University, Zaria Kaduna State, Nigeria \\ ${ }^{2}$ Nigerian Institute of Leather and Science Technology, Samaru, Zaria. Kaduna State, Nigeria. \\ *Corresponding author: yawehst2006@gmail.com
}

ABSTRACT

Response Surface Methodology (RSM) was used to investigate the effects of binder, solvent, and pigment concentrations on the coverage response. The optimum coverage response of the auto base paint formulated was $1.5 \mathrm{~m}^{2}$. Statistical analysis of the results showed that the data were adequately fitted by a second-order polynomial model. Analysis of variance (ANOVA) also showed that the interactions between the independent parameters (binder, solvent, and pigment) have significant effects on the response (coverage). Diagnostics case statistics indicated that, the optimum experimental value of the cover age equal that of the predicted. This showed a good relationship between the actual and predicted response as evidenced in the $R^{2}$ value of 0.9204 and a standard deviation of 0.1 obtained.

Keywords: Auto base paint, Binder, Coverage, Pigment, Response Surface Methodology.

\section{INTRODUCTION}

Binder, solvent, pigment, and additives form the major components of auto base paint (Ali, 2005). The interactions of these components have effects on the application properties of paint such as drying time, coverage, abrasion resistance, and adhesion (Ali, 2005; Rodger, 2008).This makes them dependent on each other which in turn enhances the properties and performance of its product (Rodger, 2008). Binder being the main ingredient plays an important role which makes it the actual filmforming component (Nanvaee et al., 2009). The common binders used in car paint formulation are polyurethane, epoxy, and alkyd resins. While the epoxy resin is only applicable for interior car top coat due to its tendency to fade and chalk when exposed to sunlight, polyurethane resin is known for its excellent chemical resistance and toughness which makes it a choice for some car paint formulators. However, alkyd resin is characterized for its lower volatile organic content (VOC) than polyurethane, good chemical resistance, excellent adhesion, fast-drying property, fairly inexpensive and its atitude of compatibility with organic solvent makes it a good choice in most industrial coatings (Nanvaee et al., 2009). Alkyd resin comes in three forms; long oil, medium oil, and short oil alkyd resin. The medium oil alkyd resin identified as (45$60) \%$ oil length is used in standard vehicle industrial coatings due to its ability to dry quickly under atmospheric conditions (Rodger, 2008;
Nanvaee et al., 2009). The quality and application properties of paint formulation depend on the right proportioning of binder and other paint components (Nanvaee et al.,2009), however, no published work has stated their proportioning clearly in auto paint formulation and its effect on drying time. In 2006, Fatemiet al. carried out the optimization of water-based road-marking paint using a mixture method of experimental design in which abrasion resistance, hardness, and pigment volume concentration were the objective functions studied. Paint and adhesive cure in automotive application formulation were also modeled by Dickieet al. in 1997, using simplified kinetic, heat transfer and structure-performance models to gain a qualitative and directional understanding of the effects of material and process parameters on the cure of paints. Several other processes have also used experimental design most especially, the surface response methodology (RSM) "which is a dynamic tool in which set of statistical design of experiment (DOE) is used and capable of aiding the relationship between out put variables with process in put decision variables to accomplish the objective of maximization of the responses" (Montgomery, 2001; Bulent et al., 2003; Arunachalam and Annadurai, 2011; Galadima et al., 2012; Uzohet al., 2013; Liet al., 2014). 
BAJOPAS Volume 12 Number 2, December, 2019

This method had been used in several processes due to its robust nature and its ability to investigate the effect of raw materials at different levels with experiments than a mixture, crossed, and factorial methods.

Fakhri (2014),optimized the process variables for fluoride ion removal with the aid of magnetite nano-particles using RSM. Keshani et al. (2010) also applied RSM in the optimization of the concentration process on pomelo fruit juice. The optimization of process conditions for tomato foam development was studied by Balasubramanian et al. (2012) using RSM. RSM was also used by Yamin et al (2013) to study lead ion removal from aqueous solution with the aid of intercalated tartrate$\mathrm{Mg}-\mathrm{Al}$ layered double hydroxides. Paint coverage as one of the important auto paint application properties has not been studied using RSM in any literature. This work, therefore, focused on the coverage response modeling for auto base paint formulation, using response surface methodology (RSM).

\section{Experimental design}

Central composite design (CCD) was employed to optimize the chosen key factors namely: binder $(A)$, solvent $(B)$, and pigment $(C)$, with the coverage response. These variables each at two levels, low and high: $A(10 \mathrm{~g}-160 \mathrm{~g}), \mathrm{B}(10 \mathrm{~g}-$ $70 \mathrm{~g})$, and $C(10 \mathrm{~g}-30 \mathrm{~g})$ are presented in Table 1. These levels were chosen based on observation from the experimental trial combination of key factors selected. The data showed in Table 1 were used as input commands that resulted in a total of 20 runs of the experiment presented in Table 2. The experimental design specifications were adhered strictly to in the laboratory, starting with run 1 , compositions where $70 \mathrm{~g}(90 \mathrm{ml})$ of mineral spirit (solvent) was measured with measuring cylinder and transferred into a mixing unit containing $0.71 \mathrm{~g}$ of an anti-settling agent to keep the solution on suspension while on mixing process with out settling down.

As the mixing process continued, $30 \mathrm{~g}$ of pigment-containing (70\% of red (ii) oxide and $30 \%$ of titanium (iv) oxide) were added and mixed until a consistent product without lumps was achieved, after which the solution was bound with $160 \mathrm{~g}$ of medium oil alkyd resin. After paint film formation was observed, $0.71 \mathrm{~g}$ each cobalt dryer, anti-skinning agent, and preservative were added to enhance the quickdrying process after application, prevent the paint from sticking to its container and also preserve it from microorganisms attack respectively. The additives added were $1.5 \%$ of the total paint formulation of raw materials used.

This procedure was repeated for the 19 other experimental runs as scheduled in Table 2 . Then, $2 \mathrm{ml}$ of the paint formulated were sprayed on substrates to determine their coverage according to ASTM 4214 standard specification (ASTM, 2009). The results obtained were inputted as a response into the design tool as shown in Table 3 and ran for analysis of variance (ANOVA).

Table 1: Design of experiment summary

\begin{tabular}{lllllll}
\hline Factors & Name & Units & $\begin{array}{l}\text { Low } \\
\text { Actual }\end{array}$ & $\begin{array}{l}\text { High } \\
\text { Actual }\end{array}$ & $\begin{array}{l}\text { Low } \\
\text { Coded }\end{array}$ & $\begin{array}{l}\text { High } \\
\text { Coded }\end{array}$ \\
\hline A & Binder & $\mathrm{g}$ & 10 & 160 & -1 & 1 \\
$\mathrm{~B}$ & Solvent & $\mathrm{g}$ & 10 & 70 & -1 & 1 \\
$\mathrm{C}$ & Pigment & $\mathrm{g}$ & 10 & 30 & -1 & 1 \\
\hline
\end{tabular}


BAJOPAS Volume 12 Number 2, December, 2019

Table 2: Variation of parameters from the experimental design

\begin{tabular}{lllll}
\hline Run & $\mathrm{A}(\mathrm{g})$ & $\mathrm{B}(\mathrm{g})$ & $\mathrm{C}(\mathrm{g})$ & Coverage $\left(\mathrm{m}^{2}\right)$ \\
\hline 1 & 160.00 & 70.00 & 30.00 & \\
2 & 10.00 & 10.00 & 10.00 & \\
3 & 85.00 & 40.00 & 20.00 & \\
4 & 10.00 & 10.00 & 30.00 & \\
5 & 10.00 & 70.00 & 30.00 & \\
6 & 41.13 & 40.00 & 20.00 & \\
7 & 160.00 & 70.00 & 10.00 & \\
8 & 85.00 & 40.00 & 03.18 & \\
9 & 160.00 & 10.00 & 30.00 & \\
10 & 85.00 & 40.00 & 20.00 & \\
11 & 85.00 & 40.00 & 20.00 & \\
12 & 85.00 & 40.00 & 36.82 & \\
13 & 160.00 & 10.00 & 10.00 & \\
14 & 10.00 & 70.00 & 10.00 & \\
15 & 85.00 & 40.00 & 20.00 & \\
16 & 85.00 & 40.00 & 20.00 & \\
17 & 85.00 & 10.45 & 20.00 & \\
18 & 85.00 & 40.00 & 20.00 & \\
19 & 85.00 & 90.45 & 20.00 & \\
20 & 211.13 & 40.00 & 20.00 & \\
\hline
\end{tabular}

\section{RESULTS AND DISCUSSION}

The results of coverage response studied in this work form variable binder, solvent, andpigment composition are presented in column five of Table3.

\begin{tabular}{|c|c|c|c|c|}
\hline Run & $A(g)$ & B (g) & $C(g)$ & Coverage $\left(\mathrm{m}^{2}\right)$ \\
\hline$\overline{1}$ & 160.00 & 70.00 & 30.00 & 1.1 \\
\hline 2 & 10.00 & 10.00 & 10.00 & 1.1 \\
\hline 3 & 85.00 & 40.00 & 20.00 & 0.7 \\
\hline 4 & 10.00 & 10.00 & 30.00 & 0.1 \\
\hline 5 & 10.00 & 70.00 & 30.00 & 0.2 \\
\hline 6 & 41.13 & 40.00 & 20.00 & 0.24 \\
\hline 7 & 160.00 & 70.00 & 10.00 & 1.3 \\
\hline 8 & 85.00 & 40.00 & 3.18 & 1.5 \\
\hline 9 & 160.00 & 10.00 & 30.00 & 0.4 \\
\hline 10 & 85.00 & 40.00 & 20.00 & 0.6 \\
\hline 11 & 85.00 & 40.00 & 20.00 & 0.6 \\
\hline 12 & 85.00 & 40.00 & 36.82 & 0.4 \\
\hline 13 & 160.00 & 10.00 & 10.00 & 1.4 \\
\hline 14 & 10.00 & 70.00 & 10.00 & 0.1 \\
\hline 15 & 85.00 & 40.00 & 20.00 & 0.5 \\
\hline 16 & 85.00 & 40.00 & 20.00 & 0.6 \\
\hline 17 & 85.00 & -10.45 & 20.00 & 0.4 \\
\hline 18 & 85.00 & 40.00 & 20.00 & 0.4 \\
\hline 19 & 85.00 & 90.45 & 20.00 & 0.4 \\
\hline 20 & 211.13 & 40 & 20.00 & 0.7 \\
\hline
\end{tabular}

As observed from the table, run 8 has the optimum coverage of $1.5 \mathrm{~m}^{2}$ from $40 \mathrm{~g}(51 \mathrm{ml})$ of solvent that is responsible for the spread of the paint film on the substrate as compared to run 1 whose solvent is $70 \mathrm{~g}(90 \mathrm{ml})$ or other runs with a higher quantity of solvent. This may be due to the right proportioning of the paint composition used (Ali, 2005), which enhanced significant effects among the factors varied (binder, solvent, and pigment) in this work. This shows that the optimum paint application properties are a function of the right composition of its raw materials during formulation. 
The coverage result obtained was used to model coverage response for auto base paint as discussed in the next subsections.

\section{Model developed}

Equation 1 showed the coverage model developed for car paint formulation. The model was developed to predict the response from the combined variable parameters that can be related and compared with the experimental response studied. $A, B$, and $C$ as shown in the equation represented binder, solvent, and pigment respectively.

$$
\text { Coverage }=\left(\begin{array}{l}
1.68667+1.13239 E-033(A)-0.012974(B)-0.065304(C) \\
-4.48614 E-006(A)^{2}-4.01470 E-005(B)^{2}+6.85707 E \\
-004(C)^{2}+5.41616 E-005(A)(B)-6.75529 E-006(A)(C) \\
+5.51234 E-004(B)(C)
\end{array}\right)^{2}
$$

The model relates the response (coverage) with the variable parameters such as a binder, solvent, and pigment.

\section{ANOVA analysis}

Table 4 showed the analysis of variance for coverage response. In the RSM study, if the value of prob $>\mathrm{F}$ is less than 0.0500 , the model studied is said to be significant (Bulent et al., 2003; Arunachalam and Annadurai, 2010; Galadima et al., 2012). As shown in Table 4, the prob>F-value of 0.0002 signifies a significant model. Thus, the model terms $A, C, C^{2}, A B$, and $B C$ whose prob> $F$-value are less than 0.0500 are significant. The lack of fit as also shown in the table is not significant which is desirable in describing a good model. However, the model has a satisfactory level of adequacy whose standard deviation was 0.1 and had an $\mathrm{R}^{2}$ value of 0.9204 .

Table 4: Analysis of variance (ANOVA) to identify significant factors affecting the coverage response

\begin{tabular}{lllllll}
\hline Source & Sum of & DF & Mean & F-Value & Prob> F & \\
& & & & & \\
Model & square & & Square & & & \\
\hline A & 1.26 & 9 & 0.14 & 12.84 & $0.0002^{*}$ & Significant \\
B & 0.44 & 1 & 0.44 & 40.68 & $<0.0001^{*}$ & \\
C & $3.816 \mathrm{E}-003$ & 1 & $3.316 \mathrm{E}-003$ & 0.35 & 0.5670 & \\
$\mathrm{~A}^{2}$ & 0.37 & 1 & 0.37 & 33.74 & $0.0002^{*}$ & \\
$\mathrm{~B}^{2}$ & $9.177 \mathrm{E}-003$ & 1 & $9.177 \mathrm{E}-003$ & 0.84 & 0.3802 & \\
$\mathrm{C}^{2}$ & 0.019 & 1 & 0.019 & 1.73 & 0.2180 & \\
$\mathrm{AB}$ & 0.068 & 1 & 0.068 & 6.22 & $0.0317^{*}$ & \\
$\mathrm{AC}$ & 0.12 & 1 & 0.12 & 10.91 & $0.0080^{*}$ & \\
BC & $2.054 \mathrm{E}-004$ & 1 & $2.054 \mathrm{E}-004$ & 0.019 & 0.8935 & \\
Residual & 0.22 & 1 & 0.22 & 20.10 & $0.0012^{*}$ & \\
Lack of Fit & 0.11 & 10 & 0.011 & & & Not \\
& 0.084 & 5 & 0.017 & 3.36 & 0.1049 & significant \\
Pure Error & 0.025 & 5 & $4.996 \mathrm{E}-003$ & & & \\
Cor Total & 1.37 & 19 & & & &
\end{tabular}

Values of "Prob $>\mathrm{F}$ " less than 0.0500 indicate model terms are significant.

Where $\mathrm{A}=$ binder, $\mathrm{B}=$ solvent and $\mathrm{C}=$ Pigment

\section{Three-dimensional surface relationship curve}

Figures $1 \mathrm{a}, 1 \mathrm{~b}$, and $1 \mathrm{c}$ show the relationship between the variable parameters (binder, solvent, and pigment) with their respective coverage response. Figure 1a shows the interaction of solvent and binder on the response, Figure $1 \mathrm{~b}$ represented the variation of pigment and binder on the response while Figure $1 \mathrm{c}$ is the pigment and solvent interactions on the response. 
BAJOPAS Volume 12 Number 2, December, 2019

As observed from Figure $1 \mathrm{a}$, as the binder contents increase with a decrease in solvent contents, the coverage response increases, this is as evidenced from the coverage response of $1.1 \mathrm{~m}^{2}$ from $160 \mathrm{~g}$ of binder and $70 \mathrm{~g}$ of solvent compositions as compared with $211.13 \mathrm{~g}$ of binder and $40 \mathrm{~g}$ of solvent compositions whose coverage response is $0.7 \mathrm{~m}^{2}$. Also, as shown in Figure $1 \mathrm{~b}$, at $160 \mathrm{~g}$ binder and $30 \mathrm{~g}$ of pigment combinations amounted to $0.4 \mathrm{~m}^{2}$ as compared to $1.3 \mathrm{~m}^{2}$ coverage response with $160 \mathrm{~g}$ binder and $10 \mathrm{~g}$ of pigment combinations.

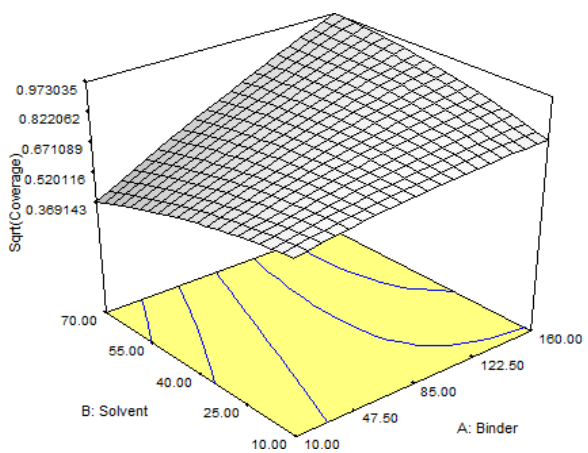

(a)
The same trend was observed in Figure1c. Relationship between the predicted and actual response

Figure 2 shows the parity plot for the predicted and actual coverage relationships. The data points as shown in the figure were well distributed close to the regression line. This signified that the actual response agrees closely with the predicted response which shows that the model developed was significant and adequate to represent the actual relationship between input variables and output response.

Figure 1: (a). Solvent-binder interaction on coverage response and (b) Pigment-binder interactions on coverage response.

Figure 1c. Pigment-solvent interaction on coverage response
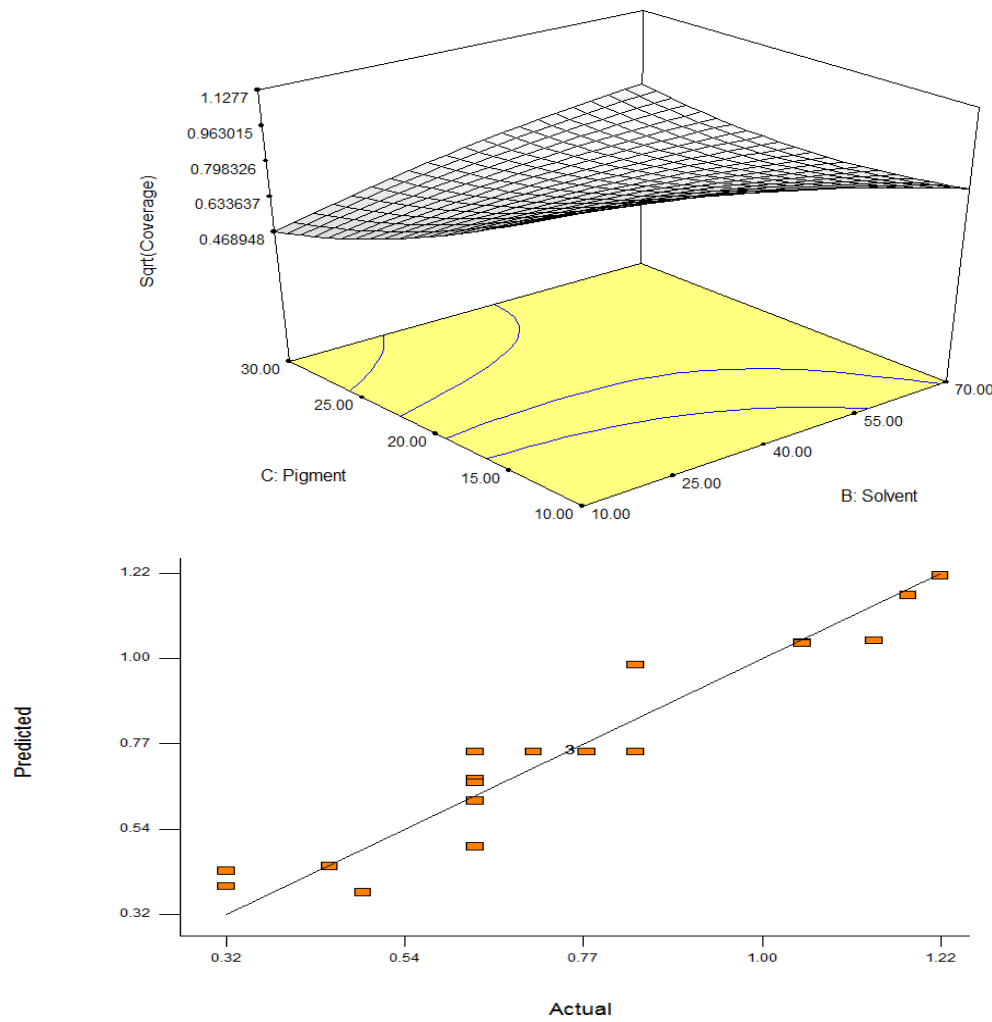

Figure 2: Predicted and actual coverage response relationship 
BAJOPAS Volume 12 Number 2, December, 2019 CONCLUSION

A model was developed for auto base paint coverage whose optimum value was $1.5 \mathrm{~m}^{2}$ using response surface methodology. The model fits experimental data, owing to the interactions between the major parameters involved that

\section{REFERENCES}

Ali, M. F. (2005). Paints, Pigments, and Industrial Coatings. Handbook of industrial chemicals: organic chemicals. McGraw-Hill, New York, 201-258.

Fakhri, A. (2014). Application of response surface methodology to optimize the process variables for fluoride ion removal using maghemite nanoparticles. Journal of Saudi Chemical Society, 18(4), 340-347

Nanvaee, A.A., Yahya, R., andGan, S. N. (2009). Alkyd Resins are Still Major Important Binders in Organic Coatings. Malaysia Polymer International Conference(MPIC, 2009),65-69.

Arunachalam, R. and Annadurai, G. (2011).Optimized RSM for Adsorption of Dyestuff from Aqueous Solution. Journal of Environmental Science and Technology, 4(1):65-72. DOI: 10.3923/jest.2011.65.

ASTM (2009) International Standard Testing and Specifications for Paints and Related Coatings. ASTM International, Worldwide.

Balasubramanian, S., Paridhi, G., Bosco J. D., and Kadam, D. M. (2012).Optimization of Process Conditions for the Development of Tomato Foam by Box-Behnken Design. Food and Nutrition Sciences, 3(7):6-7. DOI: 10.4236/fns.2012.37122.

Bulent, K. A., Murat, T., Ibrahim, H., and Hasan, V. (2003). Solar Drying of Red Peppers: Effects of Air Velocity and Particle Size. Journal of Applied Sciences, 7(5):7-9, DOI: 10.3923/jas.2007.1490.1496.

Dickie, R. A., Bauer, D. R., Ward, S. M., and Wagner. D. A. (1997). Modelling Paint and Adhesive Cure in Automotive Applications. Progess in Organic Coatings, 31(3):209-216.

Fatemi, S., Varkani, M. K., Ranjbar Z., and Bastani, S. (2006). Optimization of the Water-based Road-marking Paint by Experimental Design, Mixture Method.Progess in Organic Coatings, 55(4):337-344. DOI: were found to significantly influence the coverage response. The statistical parameters such as the $\mathrm{R}^{2}$ value of 0.9204 and a standard deviation of 0.1 obtained from ANOVA suggested good reliability of the model.

Galadima, M. S., Ahmed, A. S., Olawale A. S., and Bugaje, I. M. (2012). Optimization of Steam Distillation of Essential Oil of Eucalyptus tereticornis by Response Surface Methodology, Nigerian Journal of Basic and Applied Science, 20(4):368372.

http://www.ajol.info/index.php/njbas/ind ex.

Keshani, S., Luqman, C. A., Nourouzi, M. M., Russly A. R., and Jamilah, B. (2010). Optimization of Concentration Process on Pomelo Fruit Juice using Response Surface Methodology (RSM). International Food Research Journal, 17(3):733-742. Retrieved from http://www.ifrj.upm.edu.my/17\%20(03) $\% 202010 /$ IFRJ-2010733742\%20Keshani\%20Malaysia\%20ok. pdf.

Montgomery, D. C. (2001). Design and Analysis of Experiments. John Wiley and Sons, Incorporated, New York, 1997, 200-1.

Rodger, T. (2008). Paint Technology Handbook. CRC Press, Tailor, and Francis Group. Boca Raton, London. pp. 79-221.

Uzoh,C.F., Onukwuli, O.D., Odera,R.S., and Okey-Onyesolu,C.F. (2013). Synthesis and Characterization of Palm Oil-based Air-drying Alkyd Resin for Surface Coating. Research Journal in Engineering and Applied Science, 2(3):187-191. http://www.emergingresource.org.

Li, X., Sun, J., Cui, X., \& Wang, J. (2014). Optimization of Process Parameters for Litopenaeusvannamei Seafood Sauce using Response Surface Methodology. Advanced Journal of Food Science and Technology, 6(2):259-264.

Yamin, Y., Maszlin, M., and Faujan,B.H. (2013). The Application of Response Surface Methodology for Lead Ion Removal from Aqueous Solution using Intercalated Tartrate-Mg-Al-Layered Double Hydroxide. International Journal of Chemical Engineering, 2013(2013):2324. DOI: $10.1155 / 2013 / 937675$. 